\title{
PROCESS OF MATCHING WORK ITEMS BETWEEN BIM MODEL AND COST ESTIMATING SOFTWARE
}

\author{
Martin Stransky, Petr Dlask \\ Czech Technical University in Prague, Czech Republic \\ martin.stransky@fsv.cvut.cz,dlask@fsv.cvut.cz
}

\begin{abstract}
This article is focused on the process of matching work items into an organized structure in order to semi-automatically identify work items and link them between BIModel and cost estimating software. Several sources are suggesting a computer aided cost estimation based on historical cost data, which is a desired method of cost estimation. However, it is only achievable, if cost data are collected in an organized way and if format of cost data is structured according with defined standards. Those standards can be internal standards of a company, or national, even international standards that clearly define the structure of work items. Since work items are generally named differently throughout various bills of quantities, it should be more suitable to mark and recognize work items by numbered codes that will be defined specifically for each and every work item. The question is, what level of detail of a particular work item should these numbered codes reflect. More specifically, should these numbered codes represent a general group of work items (such as concrete grade, steel grade, size of masonry), or should they represent a detailed representation of work items (such as diameter of reinforcement, type of plaster, etc.). It also states the possible benefits for various stakeholders (client, contractor, designer, architect) throughout the life cycle of a project. It is to support the good practice of BIM in AEC industry. A semi-automatic e-procurement process is presented on the basis of matching work items into an organized structure. This semi-automatic e-procurement process is presented from the main contractor's point of view, however, it also takes into consideration other project's stakeholders. The article takes into consideration two contractual relations, these are Design - Build contract and Design - Bid - Build contract.
\end{abstract}

Keywords: BIM, cost estimation, procurement, workflow, process.

\section{Introduction}

Number of articles and literature focus on BIM methods for architects and designers, that is why BIM workflows for architects and designers are already quite well described. The author of BIG BIM and little bim walks architects through the BIM implementation process [1].Articles and literature also pay major attention towards the possibilities that BIM methods bring to owners of the built asset. Owners draw benefits throughout the whole life cycle of the built asset. Essential benefits for the owner come from early decisions made during the design and construction phases[1], because the owner can then utilize all created data and information throughout those phases in the operation phase. However, no major attention has been paid to the construction phase, namely from the contractor's and subcontractor's point of view. There is a lack of research and practical experience in procurement, cost estimation, time scheduling, and other necessary processes during the construction phase. That is why this article tackles the topic of e-procurement in AEC sector with focus on building construction [2-5]. It takes into consideration two types of contractual relations, these are Design - Build contract and Design - Bid - Build contract. It predominantly captures processes and responsibilities of the project's stakeholders from the main contractor's point of view, as well as it takes into consideration other project's stakeholders. At the end, workflows dependant of the contractual relations are presented during the bidding and construction phase.

\section{Materials and methods}

Because the construction projects are very complex in recent years, it is not common that one company does design and also construct the project. There are rather companies, which focus either on design or on construction phase [6].Typical project's stakeholders are an architect, a designer, a main contractor, number of subcontractors, consultants, and the client. Due to the fact that there are several project's stakeholders, it is necessary to share data and information between those stakeholders at various phases of the project. During the bidding phase information and data have to be transferred from the architects and designers to the main contractor in order for the main contractor to work out a tendering bid (project's cost estimation, project's time schedule, etc.). This transfer of data and information requires good means of communication and a way of sharing data and information with other project's stakeholders. Due to the variety of used data formats, it is a difficult task to share data and information in a compatible way. That is why a lot of data and information are being lost during 
the transfer process. This results in the main contractor's poor initial understanding of the project, that is why the main contractor is in risk of placing a bid, which does not correspond to the project's complexity. Therefore, some main contractors may prefer to place a higher bid with a possibility to lower their bids in upcoming bidding rounds, if required. However, this is only possible in the tendering process in the private sector, because the public sector allows only one tendering round.

It is important to point out that this article focuses on building construction rather than on road or railway construction. In the building construction sector the main contractor's cost estimator generally bases cost estimation on cost estimations of subcontractors [7]. Therefore, the main contractor's cost estimator has to place requests for quotation (RFQ) [8]onto subcontractors. Understanding this, it is quite clear that main contractor's cost estimator does not require detailed categorization of work items. What he needs is to categorize work items into groups, which represent a group of specific craft (steel structures, concrete structures, doors, windows, etc.). For example, he does not require a detailed categorization of concrete structuresinto groups of concrete grades, because he will anyway place RFQsonto subcontractors to delivery all concrete structures. The subcontractor will then categorize those concrete structures into groups of concrete grades and place a relevant bid.

Saying that, one can understand that the subcontractor's cost estimator requires detailed categorization of work items into groups, because he is the one to calculate the cost of the work items.

\section{Types of contract}

Various contractual relations require diverse workflows, thus require various project's stakeholders to take various actions and impose various responsibilities onto those stakeholders. Therefore, different standards should apply in case of different contractual relations. To better understand what is meant by that two contractual relations are given.

\subsection{Design - Build (DB) contract}

The Scheme of Design - Build contract is shown in Fig 1. In case of a Design - Build contract, there is a contractual relation between the client and the main contractor. Due to the fact, that the client and the main contractor are not an identical entity, it is necessary to use common standards between those project's stakeholders to set up and run the project. The use of standards between the main contractor and the architect and the designer can vary.If the main contractor has a department of modelers (architects and designers), then the main contractor's internal standards should be the principal standards to set up and run the project. However, if the main contractor does not have a department of modelers, then the main contractor has to make a contract with an architect and a designer. In this case it is necessary to apply both main contractor's internal standards and common standards to set up and run the project. Saying that, the main contractor can require the architect and the designer to use the parameters, which will be necessary for procurement, time scheduling, and construction management. In this way, the main contractor does not need to remodel the BIModel [9] in accordance with his internal standards, such as categorization of BIModel objects into work items, which the main contractor will use for procurement, time scheduling and construction management.

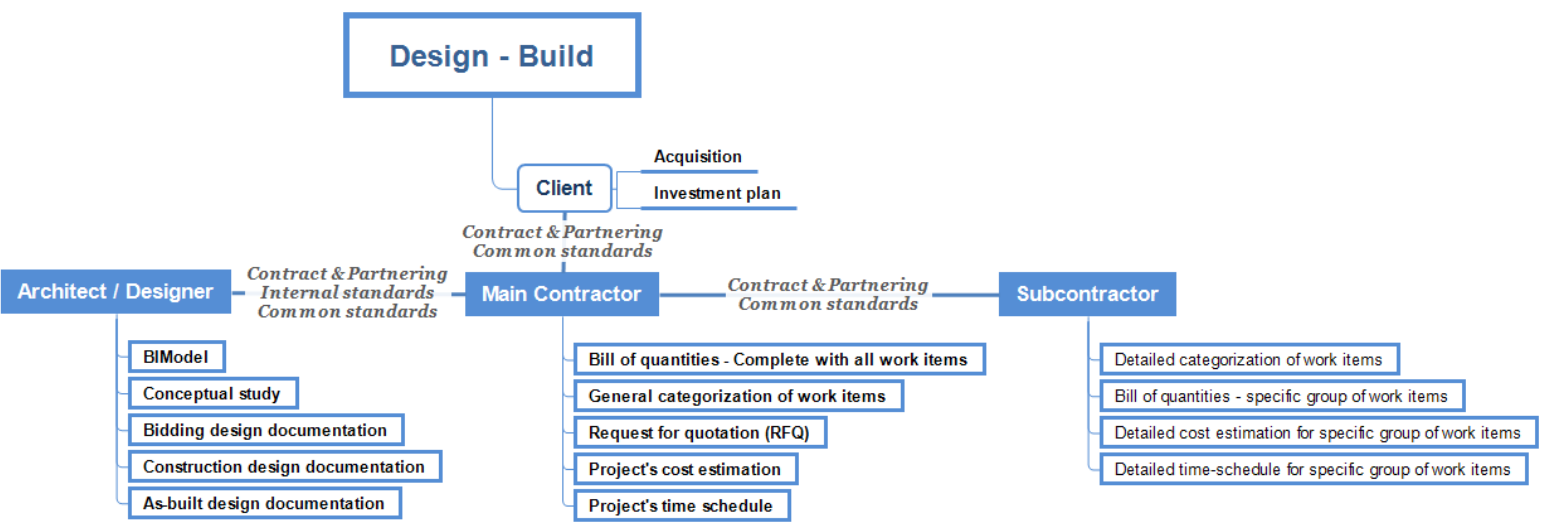

Fig. 1. Scheme of Design - Build contract 


\subsection{Design - Bid - Build (DBB) contract}

The Scheme of Design - Bid - Build contract in Fig 2. In case of a Design - Bid - Build contract, there are contractual relations between the client and the architect and the designer, and the client and the main contractor. Due to the fact, that the client, the architect and the designer, and the main contractor are not identical entities, it is necessary to use common standards between all project's stakeholders to set up and run the project. Hence, the main contractor may be required to remodel the BIModel or add important parameters to have them available for further use in procurement, time scheduling, and construction management.

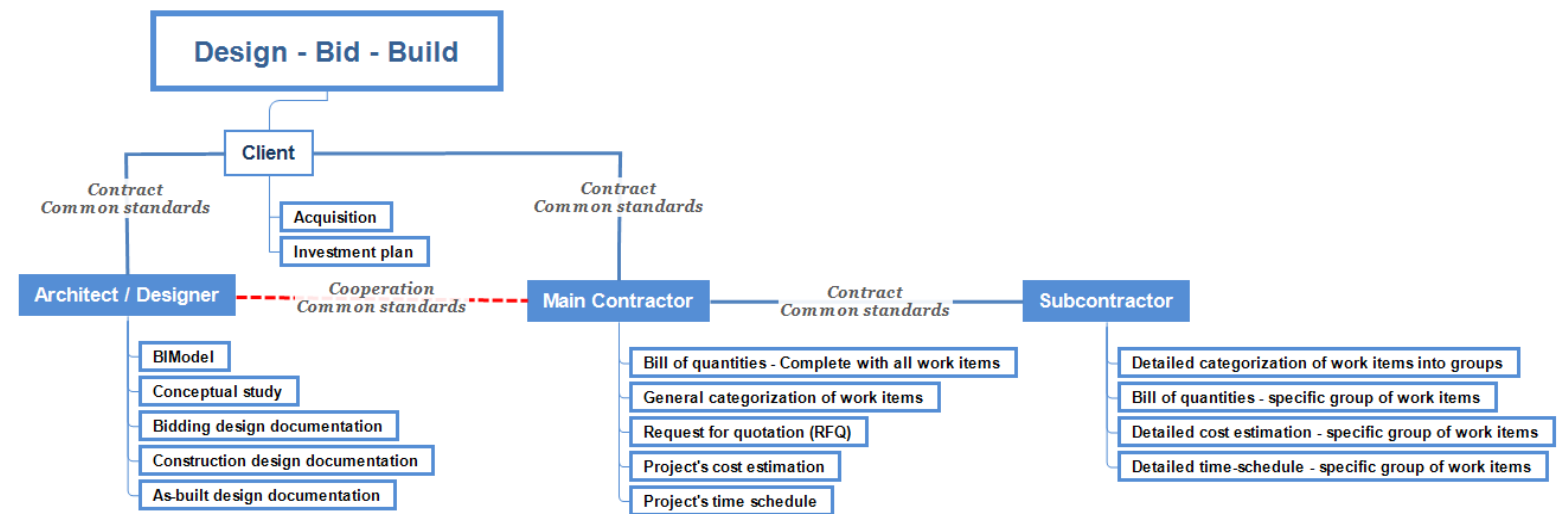

Fig. 2. Scheme of Design - Bid - Build contract

\section{Workflow depending on the contractual relations}

As to be seen from Fig. 3. a and b, there is a difference in responsibilities of project's stakeholders with the different contractual relations. That is why the workflow is also different and the project's stakeholders must act accordingly.
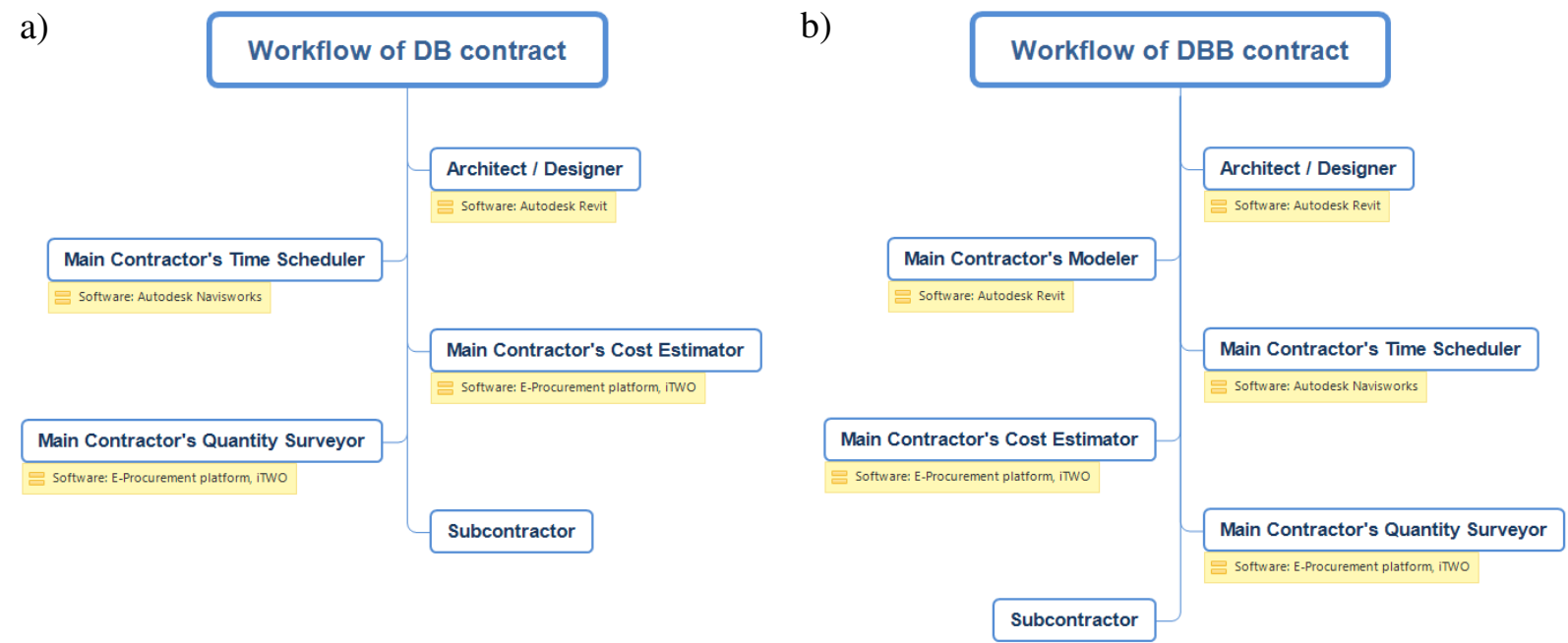

Fig. 3. Workflows of different contractual relations

\subsection{Workflow of Design - Buildcontract}

The Responsibilities and file formats of Design - Build contract is shown in Fig. 4. Due to the possibility to utilize the main contractor's internal standards between the main contractor and the architect and the designer, as stated in Paragraph 1.2, the workflow in this type of a contract is more integrated than in case of DBB contract. If main contractor's internal standards are already used during the conceptual and design phase, then the main contractor has no need for a modeler, who would need to remodel the architect's BIModel or potentially add the required parameters. In this case the main contractor can impose his internal standards onto the architect and the designer, in order to obtain the required parameters directly from the BIModel. It is not necessary for the architect and the designer to 
be internal employees of the main contractor, but it is required from them to model the BIModel in accordance with the main contractor's internal standards. Only in this case the main contractor can obtain the necessary parameters for his processes.

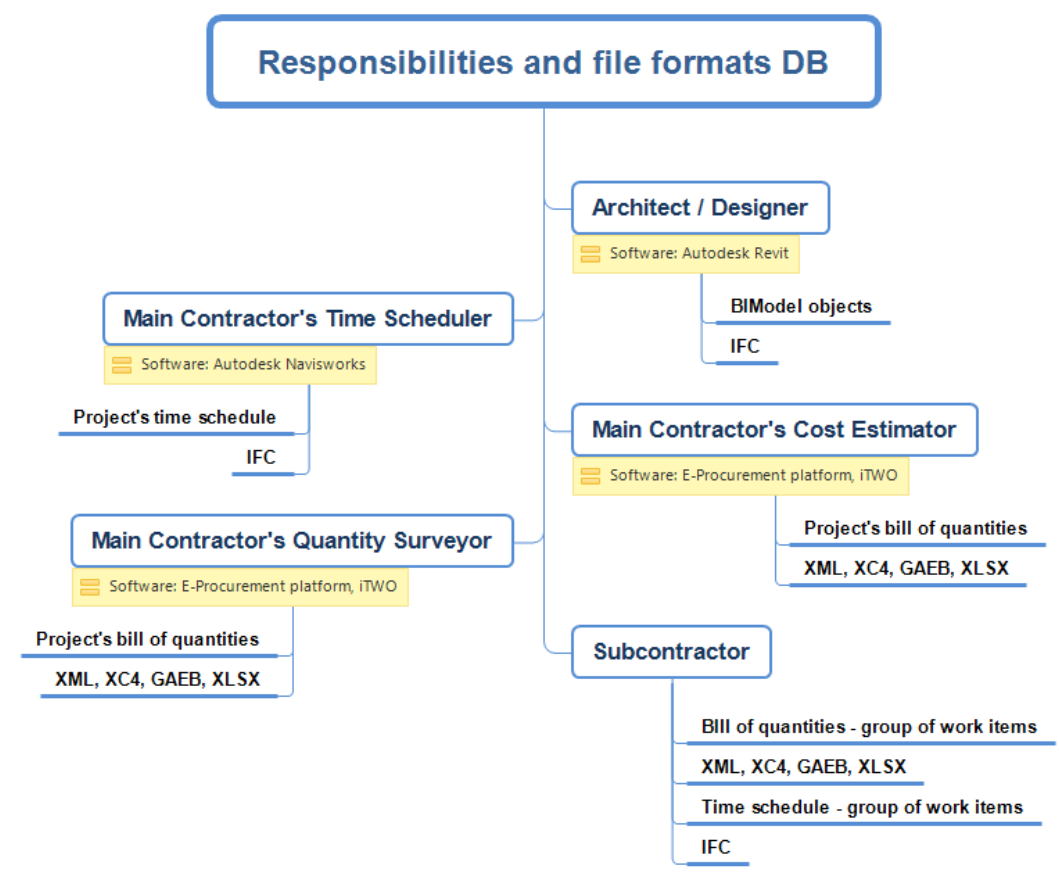

Fig. 4. Responsibilities and file formats of Design - Build contract

\subsubsection{Responsibilities of project's stakeholders}

The architect and the designer shall model BIModel in compliance with the main contractor's internal standards and also with the common standards. The main contractor's internal standards shall specify a coding system for categorization of BIModel objects into work items [10], and for categorization of construction drawings. This coding system will enable the main contractor to fluently proceed with his processes (procurement, time scheduling, etc.).Common standards shall specify other requirements onto the architect and the designer for sharing data and information to other project's stakeholders. The Work outputs of Architect/Designer with suggested software tool is shown in Fig. 6 .

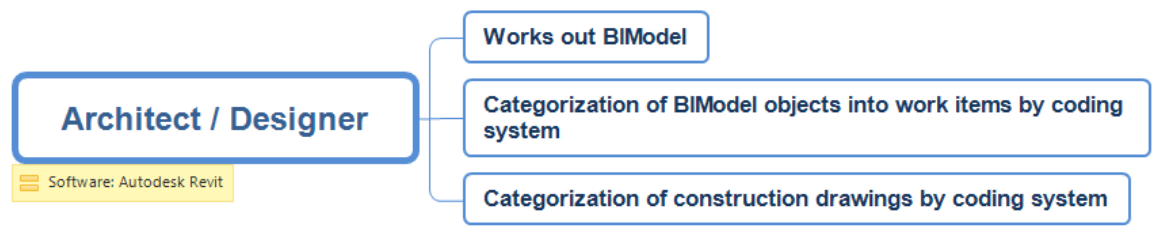

Fig. 5. Work outputs of Architect/Designer with suggested software tool

The main contractor's time scheduler shall utilize the architect's BIModel to work out the project's time schedule. The time scheduler shall import the architect's BIModel into a time scheduling software to work out the project's time schedule. If the time scheduling software allows for cloud computing[11], then he shall work out the project's time schedule on the cloud. As far as BIModel objects are already categorized into work items by coding system, the time scheduler can semi-automatically generate a hierarchy of the project's time schedule. The time scheduler may use historical data of time requirements of each work item to establish preliminary project's time schedule. Then he shall crosscheck and edit dependencies between the work items and adjust their time duration regarding the needs of particular projects. The Work outputs of main contractor's time scheduler with suggested software tool is shown in Fig. 6. 


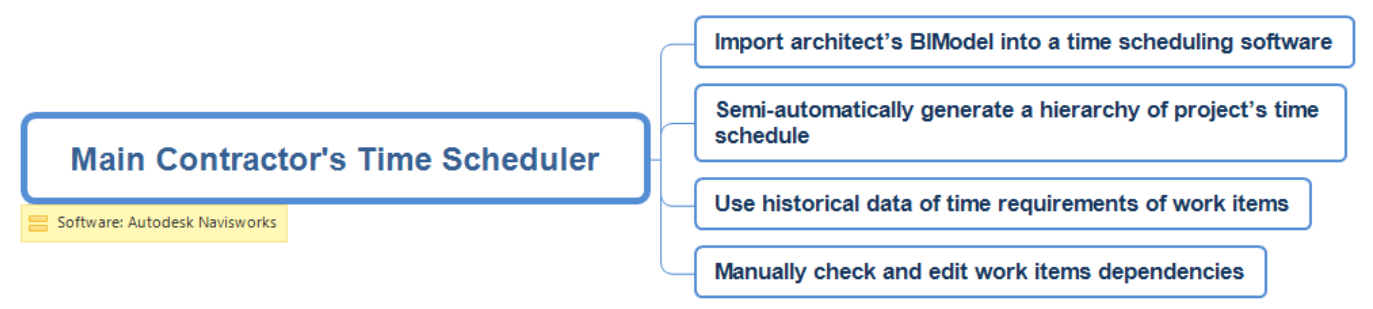

\section{Fig. 6. Work outputs of main contractor's time scheduler with suggested software tool}

The main contractor's cost estimator shall utilize the architect's BIModel to work out the project's cost estimation. He shall import the architect's BIModel into a cost estimating software, to work out the project's cost estimation. As far as BIModel objects are already categorized into work items by the coding system, the cost estimator can semi-automatically generate a hierarchy of the project's bill of quantities. The cost estimator may use cost historical data of each work item to create preliminary project's cost estimation. If no cost historical data are available, then shall the main contractor's cost estimator place RFQs onto subcontractors, who shall provide their bids. This process is further described in the following paragraph. The process of sending RFQs onto subcontractors is preferred due to highly competitive construction market, changes in actual cost of work items, and due to complex technical solutions that require a specialist to estimate a competitive cost. That is why the main contractor's cost estimator shall generally base his cost estimation on subcontractor's bids rather than on cost historical data to be successful in the bidding phase. Cost historical data shall be preferably used for estimating the cost of construction site facilities, works performed by the main contractor, internal overhead expenses, as well as for the cost estimation of amendments. The Work outputs of main contractor's cost estimator with suggested software tool is shown in Fig. 7.

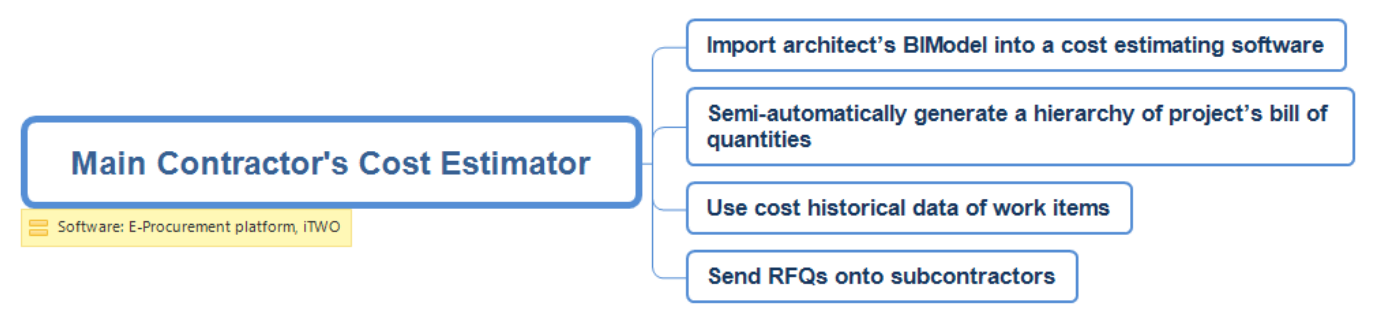

Fig. 7. Work outputs of main contractor's cost estimator with suggested software tool

The main contractor's quantity surveyor shall utilize the architect's BIModel for procurement of subcontractors. As far as the architect already categorized BIModel objects into work items by the coding system, the quantity surveyor has all construction drawings relevant to a specific group of work items available. As the time scheduler already prepared the project's time schedule categorized into work items by the coding system, the quantity surveyor has the time schedule of all groups of work items available. As the cost estimator already worked out project's cost estimation categorized into work items by the coding system, the quantity surveyor has cost estimation of all groups of work items available. Therefore, he has all necessary data and information to start procurement of subcontractors. An e-procurement platform shall extract all available data and information provided by other project's stakeholders. For a specific group of work items the following shall be known and available; budget (bill of quantities), time schedule, corresponding construction drawings and the BIModel. The quantity surveyor shall work out the following outputs. The procurement time schedule (date to send RFQs, duration of tendering phase, date to sign a contract, and other deadlines), bill of quantities specific to a group of work items, sort out complete design documentation onto packages of design documentation relevant to a specific group of work items, list of potential subcontractors, prepare template forms related to procurement. An e-procurement platform shall assist the quantity surveyor in these tasks as follows:

Based on the project's time schedule in combination with the fabrication time historical data, an e-procurement platform shall propose the quantity surveyor a preliminary procurement time schedule. A procurement time schedule shall be categorized into groups of work items. Each group of work items shall include its construction duration based on the project's time schedule and its expected 
fabrication duration based on the fabrication time historical data or information provided by subcontractors during the bidding phase. This will provide the quantity surveyor with deadlines, when he shall start the procurement of a specific group of work items and when construction of this specific group of work items will commence. This will give the quantity surveyor a period that he has for procurement of a given group of work items. An e-procurement platform should also allow for monitoring of the procurement process (when RFQs were sent, when subcontractors responded, etc.).

Based on the project's cost estimation an e-procurement platform shall propose the quantity surveyor a specific bill of quantities to groups of work items. This will provide a budget and a specific bill of quantities for each group of work items. This bill of quantities will serve as an attachment for RFQs sent to subcontractors. Subcontractors will import this bill of quantities into their cost estimating software and work out a bid, which they will send back to the quantity surveyor for evaluation.

Based on the project's design documentation an e-procurement platform will propose the quantity surveyor construction drawings related to a given group of work items. It is common, that specific crafts have their specific design documentation(e.g., concrete, steel, locksmith, tinsmith structures, doors, windows, ventilation system, etc.). Construction drawings shall be categorized by the same coding system as the work items are. This will provide the quantity surveyor with the corresponding design documentation to each group of work items. Of course, the BIModel will be provided at the same time.

An essential feature of an e-procurement platform is a database of subcontractors. Each subcontractor shall be assigned with a portfolio of groups of work items that he can perform. This will propose the quantity surveyor a selection of subcontractors for each group of work items. Further a geolocation of the subcontractor could be added to select a distance range to filter subcontractors.

The quantity surveyor should submit all above stated to selected subcontractors through RFQs.

The Work outputs of main contractor's quantity surveyor with suggested software tool is shown in Fig. 8.

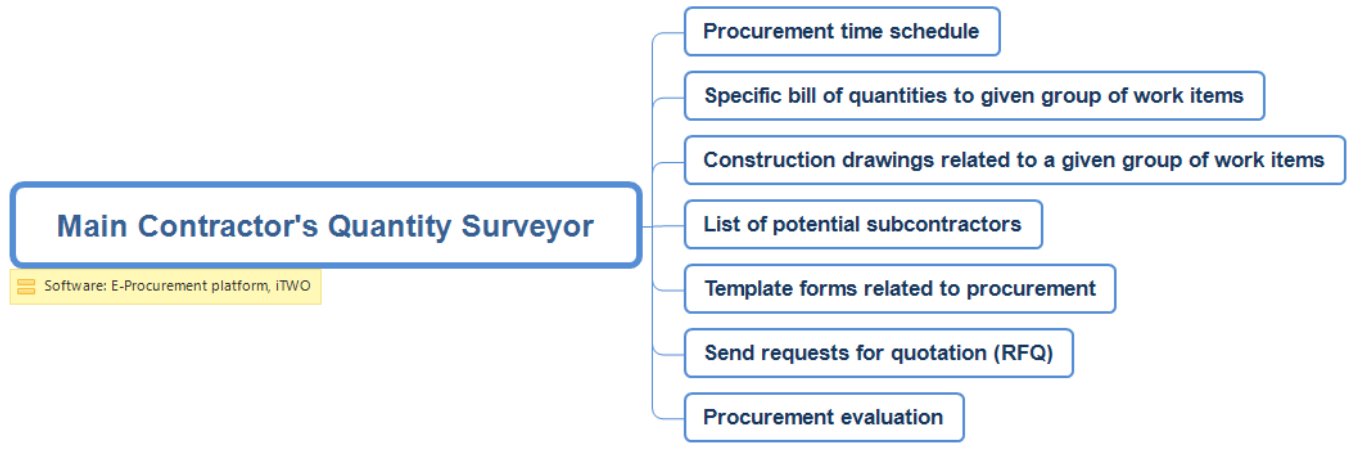

Fig. 8. Work outputs of main contractor's quantity surveyor with suggested software tool

The subcontractor shall receive all relevant data through an e-procurement platform from the quantity surveyor to work out his detailed cost estimation and time schedule specific to a given group of work items. Once the subcontractor works out all necessary data, he shall send his bid back to the quantity surveyor for evaluation.

The Work outputs of subcontractor is shown in Fig. 9.

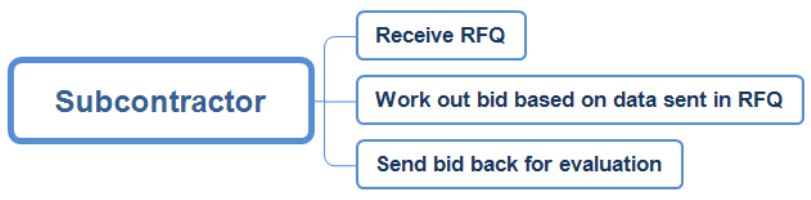

Fig. 9. Work outputs of subcontractor 


\subsection{Workflow of Design - Bid - Build contract}

The Responsibilities and file formats of Design - Bid -Build contract is shown in Fig. 10. Due to the fact that there is no contractual relation between the main contractor and the architect and the designer, the main contractor has a need for a modeler. The modeler will remodel the architect's BIModel, or would potentially add the required parameters into the architect's BIModel in compliance with the main contractor's internal standards.

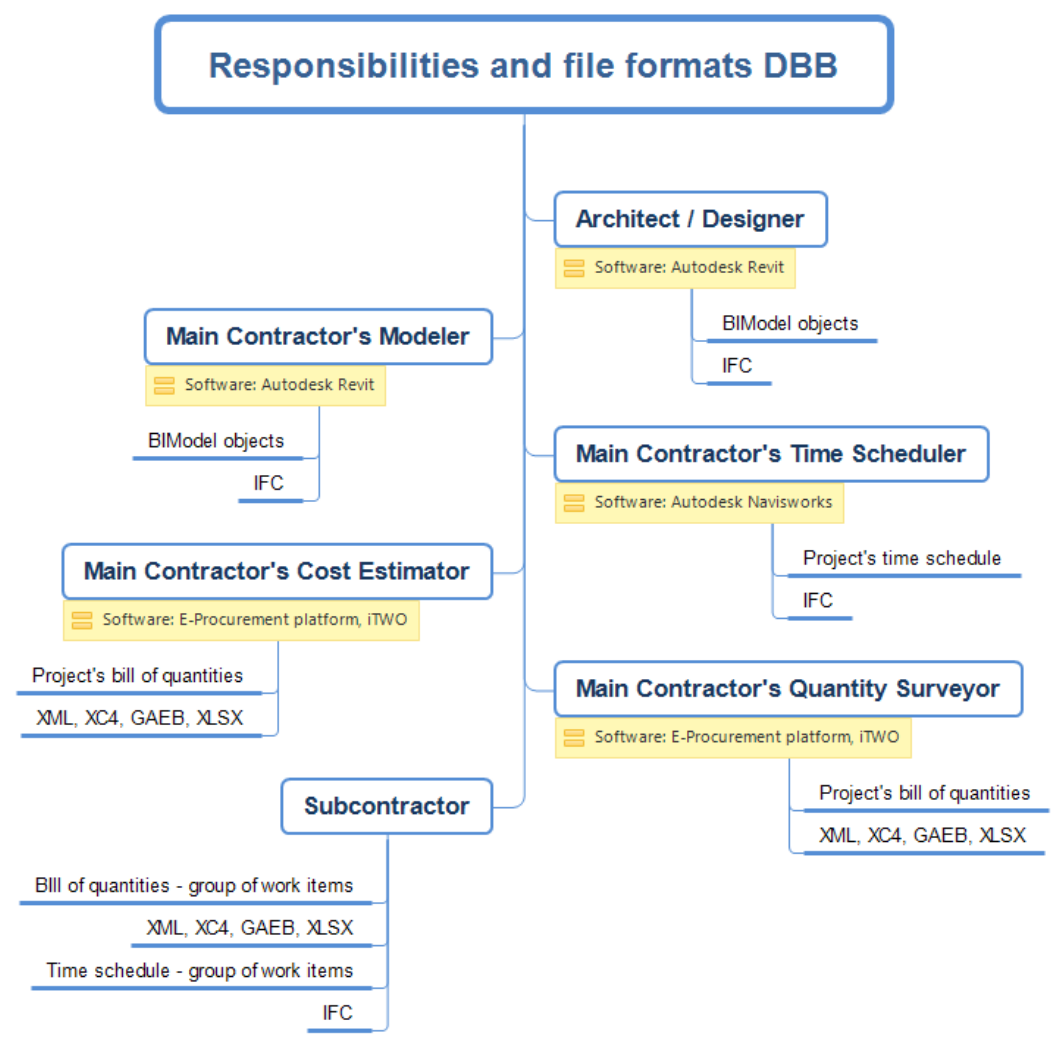

Fig. 10. Responsibilities and file formats of Design - Bid -Build contract

\subsubsection{Responsibilities of project's stakeholders}

As far as there is no contractual relation between the main contractor and the architect and the designer, plus the design phase occurs before the main contractor is awarded the project, it is very unlikely that the architect and the designer will model the BIModel in compliance with the main contractor's internal standards. That is why the architect and the designer shall model the BIModel in compliance with the common standards.

Due to the fact that the architect and the designer did not model the BIModel in compliance with the main contractor's internal standards, the main contractor has a need for a modeler. The modeler has two options, whether he remodels the architect's BIModel using the main contractor's BIM objects library, or he categorizes the BIM objects within the architect's BIModel using the main contractor's internal standards and the coding system of work items. It is also possible that the main contractor makes a contract with an external modeler to remodel the initial BIModel. This is subject to individual project. The Work outputs of main contractor's modeler with suggested software tool is shown in Fig. 11.

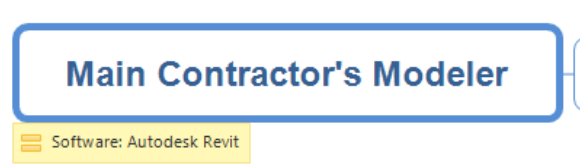

Remodel the architect's/designer's BIModel

Edit the architect's/designer's BIModel

Fig. 11. Work outputs of main contractor's modeler with suggested software tool 
Workflow of the main contractor's time scheduler, cost estimator, and quantity surveyor, and subcontractor should be identical as in case of the Design - Build contract. There will be a change in communication since a modeler is introduced into the process. That is why this workflow is found to be not as effective as the workflow in the Design - Build contract, where the main contractor's stakeholders communicate changes directly with the architect and the designer, rather than communicating them with the modeler, who has to coordinate changes with the architect and the designer.

\section{Results and discussion}

It was found that a Design - Build contract is more suitable for an integrated process due to several reasons. Partnering between the main contractor and the architect and the designer starts early in the design phase, where decisions bear small cost but have major impact on the project's cost. As the main contractor participates in the project from an early phase, it results in his better understanding of the project, therefore the risk of placing an inaccurate bid tends is lower. As fluent workflows are a key point of an integrated process, the Design - Build contract is a spine of it. Only if the main contractor works on the project with the architect and the designer from an early stage, the BIModel can be prepared for processes of the main contractor. Otherwise the main contractor has a need for a modeller, who would remodel the architect's BIModel or he would add the required parameters for the main contractor into the architect's BIModel. This will create a mundane work that has to be avoided by all means. Another aspect is the fact that another project's stakeholder is introduced, which brings higher possibility of miscommunication and therefore higher possibility of mistakes.

An e-procurement process for managing projects was introduced. This e-procurement process was put into context of outputs of various project's stakeholders. It was shown that it does rely on highquality outputs of various project's stakeholders. That is, that following project's stakeholders have to do their work in compliance with the main contractor's internal standards and common standards:

- architect and designer have to model their BIModel;

- main contractor's time scheduler has to work out the project's time schedule;

- main contractor's cost estimator has to work out the project's cost estimation;

- main contractor's quantity surveyor has to lead procurement of subcontractors;

- and the subcontractor has to work out his bid.

This e-procurement process should be applicable in an e-procurement application. The question is if such an e-procurement application should be web-based or a local application. Who should have access to this application, which databases it shall utilizes, who would add data into the databases, how will it be connected to listed software tools in this article, and further questions are still to be researched. However, this is not the scope of this research paper and thus it should be a research topic of future articles.

\section{Conclusions}

1. BIModel objects shall be categorized into work items by a coding system.

2. Utilization of a coding system has a major influence on transparency and consistency of created data and information throughout the project's life cycle.

3. These data and information can be easily withdrawn in the subsequent phases, because all data and information are tagged by this coding system.

4. An e-procurement process can mitigate mundane work and thus improve workflows.

5. This e-procurement process supports the creation of high quality outputs of project's stakeholders and connects them into one platform.

6. Presented workflows introduce semi-automatic methods to provide outputs of various project's stakeholders, however, these outputs shall be examined and edited, if necessary.

7. Based on contractual relationship internal or common standards shall be used between various project's stakeholders.

8. Project's stakeholders have to do their work in compliance with common and internal standards.

9. Cooperation between project's stakeholders from an early stage is essential for early decisions. 
10. Project's stakeholders shall utilize the maximum information and data provided by the preceded project's stakeholder to work out their outputs.

11. Design - Build contract is more suitable for an integrated process than the Design - Bid - Build contract.

\section{Acknowledgements}

This work was supported by the Grant Agency of the Czech Technical University in Prague, grant No. SGS17/121/OHK1/2T/11.

\section{References}

[1] Jernigan F.E. BIG BIM, little bim. Second edition. Salisbury: 4Site Press, 2008.

[2] Grilo A., Jardim-Goncalves R. Challenging electronic procurement in the AEC sector: A BIMbased integrated perspective. Automation in Construction,vol. 20, Issue 2, 2011, pp. 107-114. [online][19.03.2018]. Available at:

http://www.sciencedirect.com/science/article/pii/S0926580510001378.

[3] Jardim-Goncalves R., Grilo A. SOA4BIM: Putting the building and construction industry in the Single European Information Space. Automation in Construction, vol. 19, Issue 4, 2010, pp. 388-397. [online][19.03.2018]. Available at: http://www.sciencedirect.com/science/article/pii/S0926580509001794.

[4] Gunasekaran A., McGaughey R.E., Ngai E.W.T., Rai B.K. E-Procurement adoption in the Southcoast SMEs. International Journal of Production Economics, vol. 122, Issue 1, 2009, pp. 161-175. [online][19.03.2018]. Available at: http://www.sciencedirect.com/science/article/pii/S092552730900173X.

[5] Gunasekaran A., Ngai E.W.T. Adoption of e-procurement in Hong Kong: An empirical research. International Journal of Production Economics, vol. 113, Issue 1, 2008, pp. 159-175. [online][19.03.2018]. Available at: http://www.sciencedirect.com/science/article/pii/S0925527307002514.

[6] Creed S.J.E Seok H.Y., Joon H.P. Subcontractor Evaluation and Management Framework for Strategic Partnering. Journal of Construction Engineering and Management, vol. 134, Issue 11, 2008, pp. 842-851. [online] [19.03.2018]. Available at: https://doi.org/10.1061/(ASCE)07339364(2008)134:11(842).

[7] Hinze J., Tracy A. The Contractor-Subcontractor Relationship: The Subcontractor's View. Journal of Construction Engineering and Management, vol. 120, Issue 2, 1994, pp. 274-287. [online] [19.03.2018]. Available at: https://doi.org/10.1061/(ASCE)07339364(1994)120:2(274).

[8] Request for quotation. [online][19.03.2018]. Available at: http://www.businessdictionary.com/definition/request-for-quotations-RFQ.html.

[9] BIM Dictionary. [online][19.03.2018]. Available at: https://bimdictionary.com/en/bimodel/1/.

[10] Vitásek S., Matějka P. Utilization of BIM for automation of quantity takeoffs and cost estimation in transport infrastructure construction projects in the Czech Republic. IOP Conference Series: Materials Science and Engineering, September 21-22, 2017, Prague, Czech Republic, vol. 236, art. no. 012110.

[11] Grilo A., Jardim-Goncalves R. Cloud-Marketplaces: Distributed e-procurement for the AEC sector. Advanced Engineering Informatics, vol. 27, Issue 2, 2013, pp. 160-172. [online][19.03.2018]. Available at:

http://www.sciencedirect.com/science/article/pii/S1474034612000973. 